\title{
Acne in schoolchildren: no longer a concern for dermatologists
}

\author{
M Rademaker, J J Garioch, N B Simpson
}

\begin{abstract}
Objective-To determine the prevalence and severity of acne among schoolchildren in Glasgow.

Design-Secondary schools in Glasgow were divided by postcode into five socioeconomic cluster groups. Different numbers of schools were selected at random from the five groups to ensure proportional representation. One class from each registration year of the chosen schools was selected at random and the whole class recruited into the study.

Setting - 15 Secondary schools in Glasgow.

Subjects-2014 Randomly selected schoolchildren aged $12-17$ (5\% of total secondary school roll).

Interventions-None.

End point-Assessment of facial acne by two independent examiners by a recognised acne scoring system.

Measurements and main results - The prevalence of acne in boys increased from $40 \%(75 / 189)$ at age 12 to $95 \%(108 / 114)$ at age 16 , and in girls it increased from $61 \%(114 / 187)$ at age 12 to $83 \%(136 / 164)$ at age 16 . On a scale of 0 to 10 only 18 boys $(1.8 \%)$ and three girls $(0.3 \%)$ had grades of acne of 1.0 or greater; most of the pupils had grade 0.05-0.375 (minimal) acne. Nine per cent of boys $(88 / 973)$ and $14 \%$ of girls (145/ 1041) had visited their general practitioner specifically for advice on and treatment for acne; only five pupils $(0 \cdot 3 \%)$ had been referred to a dermatologist.

Conclusions-Both the prevalence and severity of acne have decreased over the past 20 years. This has probably been due to improvement of treatment for acne by primary care doctors and the greater availability and use of over the counter preparations for acne.
\end{abstract}

\section{Introduction}

A person is more likely to suffer from acne than any other disease; previous estimates have suggested a prevalence as high as $100 \% .^{1}$ The implications of such a common disease for health care are important, and any change in the prevalence or incidence should be noted. Over the past few years we have found it increasingly difficult to recruit young adolescents for clinical trials in acne owing to an apparent decrease in the severity of acne. We therefore set out to establish the prevalence and severity of facial acne among secondary school children in Glasgow. An important criticism of previous studies on the prevalence of acne has been the non-random selection of the study populations - for example, by place of work $^{2}$ or educational institution. ${ }^{34}$ We selected a random sample of the population for our study.

Department of

Dermatology, Glasgow

Royal Infirmary, Glasgow G4 OSF

M Rademaker, MRCP, senior registrar

J J Garioch, MRCP, registrar

N B Simpson, MD, consultant

Correspondence to: $\mathrm{Dr}$ Rademaker.

Br.Med F 1989;298:1217-20 minimum sample size required to produce sufficien numbers of cases of severe acne (score $>1.0$ ) to make statistical comparisons was about 2000 children. In secondary school pupils (aged 12-18) in 66 schools (35 Glasgow (population 986671) there were 42254 non-denominational, 20 denominational, and 11

\section{Housing conditions determining the five socioeconomic cluster groups that divide Glasgow by postcode}

(A) Owner occupied housing: families with young children; professional and non-manual workers

(B) Mixed tenure type housing: high proportion of families with no children, single people, and students; non-manual and professional workers. Interwar local authority housing: elderly people

(C) Postwar local authority housing: young families; skilled workers. Small, rented, furnished, and owner occupied households with shared amenities: single people, students, and immigrants

(D) Postwar local authority housing: young families; unemployed people, unskilled workers

(E) Local authority housing, vacant properties, and small, overcrowded households with shared amenities: unemployed people, unskilled workers

independent) in 1987-8; the average class contained 25 30 pupils. Secondary schools cover all social classes, but the pupils are not allocated randomly by social class through the schools. To overcome this problem we separated the schools by using a socioeconomic scale developed by Greater Glasgow Health Board. Glasgow and its 66 schools were divided according to postcode into five socioeconomic cluster groups (box). As schools generally draw their intake from the local population we were able to estimate the socioeconomic background of the pupils by choosing schools representative of a particular postcode.

Schools representative of each socioeconomic cluster group were entered into a randomisation schedule. Different numbers of schools were selected at random from the five groups to ensure proportional representation. Fifteen schools were chosen, and one class from each registration year was selected at random; the whole class was then recruited into the study-for example, in cluster group C (population 193 064; 20\% of the total population of Glasgow) there were 12 secondary schools with a total of 7517 secondary pupils ( $18 \%$ of all secondary school children). Three schools from this cluster group were selected randomly and $388(19 \%)$ children examined.

All pupils were asked to complete a questionnaire asking whether they thought that they had spots, and if so, at what age these had first appeared; and whether they had asked anyone for advice about their spots and, if so, whom they had asked. They were also asked whether they had ever seen their family doctor or a specialist about acne and what treatments, if any, they had used (given 12 choices of treatments that were available either with or without a prescription). The face of each pupil was then examined independently by two doctors with a large, hand held, illuminated magnifying glass.

Acne was scored according to a scoring system ${ }^{5}$ of 0 to 10: 0 represented no acne; $0.05,0.1,0.175,0.25$, and 0.375 represented increasing numbers of comedones and non-inflammatory papules; $0.5,0.75$, $1 \cdot 0,1 \cdot 25$, and 1.5 represented increasing numbers of 
comedones and inflammatory papules with occasional pustules; 1.75 to 3.5 represented increasing numbers of comedones, inflammatory papules, and pustules; and 4.0 to 10.0 represented increasing numbers of pustules, nodules, and cysts. To compare the results of this study with those of previous studies the acne scores were divided into five grades: no acne (score 0), minimal acne $(0.05$ to 0.375$)$, mild acne $(0.5$ to 1.5$)$, moderate acne $(1.75$ to $3 \cdot 5)$, and severe acne $(4 \cdot 0$ to $10 \cdot 0)$.

Approval for the study was obtained from Glasgow Royal Infirmary's ethical committee, the Strathclyde department of education, and the headmasters of the schools concerned. Parents were informed of their children's participation by the schools, and any child who did not wish to take part in the study was excluded.

\section{Results}

A total of 2022 pupils were recruited from 15 schools. Five pupils were not examined either because their parents did not give consent or because they did not wish to take part in the study. There was complete concordance between the acne scores recorded by the two examining doctors for 1567 pupils, a difference of one acne score for 417 pupils, and a difference of two scores for 30 pupils (all differences occurred within scores $0 \cdot 05-0 \cdot 375$ ). The two doctors differed by three scores in three pupils; we therefore analysed the results for 2014 pupils. There were 973 boys and 1041 girls. Three hundred and four pupils came from socioeconomic cluster group A and 374, 388, 454, and 494 from cluster groups B, C, D, and E respectively.

Five hundred and ninety four boys $(61 \%)$ and 858 girls $(82 \%)$ thought that they had spots. The median age at onset of spots in these pupils was 12 years in girls and 13 years in boys. Three hundred and forty boys $(57 \%)$ and 519 girls $(60 \%)$ who considered that they had spots had asked for advice on treatment. Most had sought advice from their families (table), although 88 boys $(15 \%)$ and 145 girls $(17 \%)$ said that they had been to their family doctor specifically for treatment for acne. Only five of these pupils had been referred to a dermatologist.

Sources of advice sought by schoolchildren aged 12-17 who though they had spots. Values are numbers (percentages)

\begin{tabular}{|c|c|c|}
\hline & Boys $(n=594)$ & Girls $(n=858)$ \\
\hline Did not seek advice & $254(43)$ & $336(39)$ \\
\hline $\begin{array}{l}\text { Sought advice } \\
\text { Friend }\end{array}$ & $48(8)^{340(57)}$ & $104(12)$ \\
\hline Family & $240(40)$ & $349(41)$ \\
\hline Chemist & $18(3)$ & $27(3)$ \\
\hline Family doctor & $88(15)$ & $145(17)$ \\
\hline Dermatologist & $3(1)$ & $2(0)$ \\
\hline Other & $11(2)$ & $10(1)$ \\
\hline
\end{tabular}

Three hundred and thirty six boys (35\%) had used treatment compared with 603 girls $(58 \%)$. Two hundred and thirty seven boys (24\%) and 472 girls $(45 \%)$ had used one treatment, 82 boys $(8 \%)$ and 135 girls (13\%) had used two treatments, and 17 boys (2\%) and 23 girls $(2 \%)$ had used three or more different treatments. Most of these were available without a prescription but 37 boys ( $4 \%$ ) and 28 girls (3\%) said that they had been prescribed systemic antibiotics for their acne.

Figure 1 shows the results for the grades of acne. On the day of examination $292(30 \%)$ boys and $238(23 \%)$ girls had no acne, most of these being $12-14$ years old. The prevalence of acne increased in girls from $61 \%$ at age 12 to $85 \%$ at 17 and in boys it increased from $40 \%$ at age 12 to $93 \%$ at 17 (fig 2). There was no correlation between the socioeconomic cluster group and the

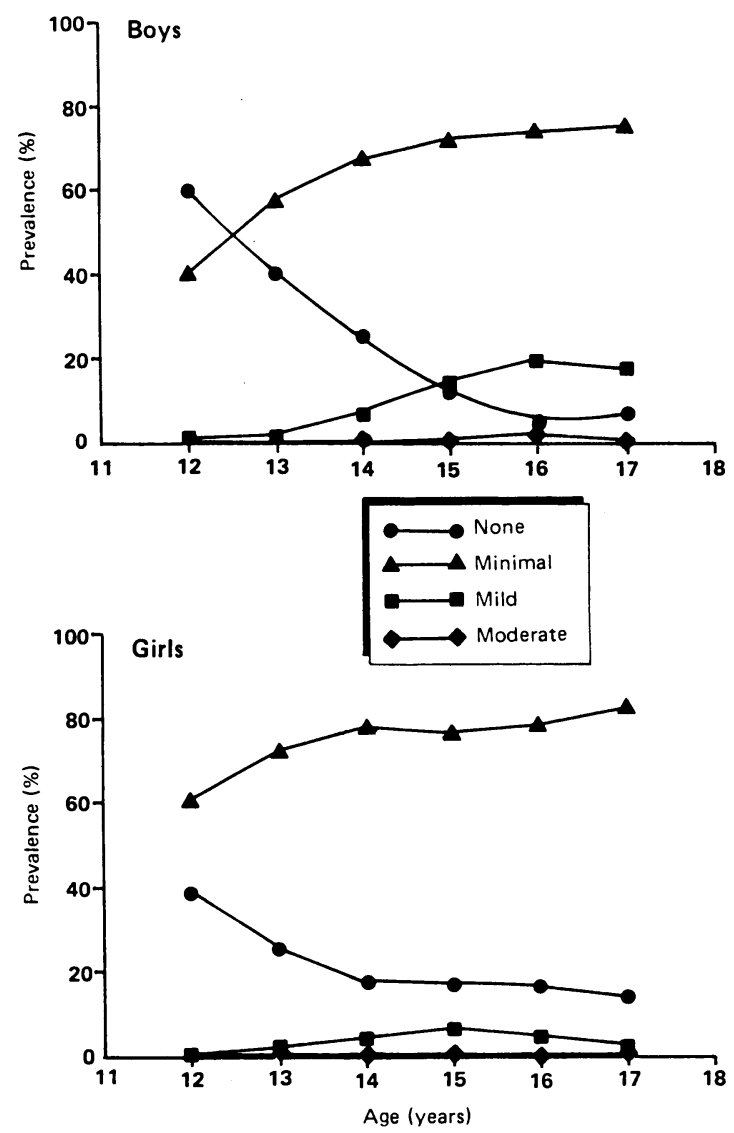

FIG 1-Severity of acne in schoolchildren aged 12-17

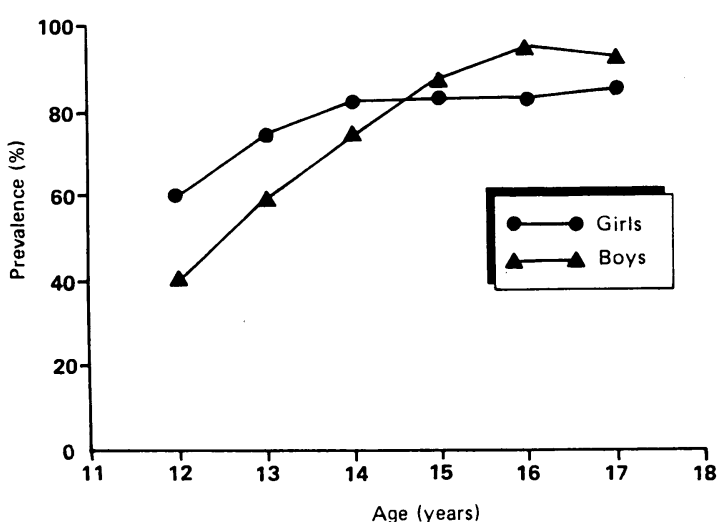

FIG 2-Prevalence of acne in schoolchildren aged 12-17

presence or absence of acne, the acne score or grade, or the pupils' perception of spots. Girls were better at discerning whether they had acne: 94 girls $(\mathbf{9 \%})$ said that they did not have spots but were considered by the two examining doctors to have acne, whereas 175 boys (18\%) who considered themselves to be free of spots were considered to have acne.

\section{Discussion}

There have been few epidemiological studies of acne. The strength of this study lies in its random selection of adolescents across the social classes. We limited the study to 12-17 year olds (first to fifth forms) as the sixth form (aged 18) is no longer representative of the community because a greater proportion of children from the lower socioeconomic groups leave school after the fifth form. Similarly, university and college students, army recruits, and unemployed youths are not representative samples of the community.

The prevalences of acne in previous studies varied from $38 \%$ to $100 \%$ in girls and from $51 \%$ to $100 \%$ in 
boys. ${ }^{1467}$ This variation is due to differences in the definition of acne (that is, whether or not comedones were included in the definition). Bloch, defining acne as the presence of more than one comedone, examined 4191 children aged 6-19 (2076 children aged 12-17) and found that the prevalence of acne increased from $13 \%$ to $97 \%$ in girls (aged 6 and 17 respectively) and from $12 \%$ to $99 \%$ in boys. ${ }^{6}$ Burton et al, who defined acnè in a similar manner, reported a prevalence of $100 \%$ in girls aged 14 and boys aged $15 .{ }^{1}$ Fellows $e t$ al, who in a longitudinal study of 1500 children defined acne as the presence of papules and pustules but excluded simple comedones, reported an increasing prevalence, from $1.3 \%$ to $78 \%$ in girls (aged 10 and 15 respectively) and from $0 \%$ to $87 \%$ in boys (aged 10 and 16.5 respectively).

The apparent fall in the prevalence of acne in our study compared with that of Burton et al 20 years ago may not be important. ${ }^{1}$ We were careful to include a single comedone as representing acne vulgaris, but we cannot say that a "snapshot" view of acne on one day means that $15 \%$ of girls and $7 \%$ of boys are never going to develop acne. We agree with Kligman's argument that the social impact of acne is due to its severity and not simply its presence (which he assumed to be $100 \%) .{ }^{8}$ Of greater interest is the fall in the severity of acne over the past 50 years. It is difficult to compare the results of previous studies as they all used different scales for grading acne. For comparison with other studies we arranged our results into five groups: no acne, minimal acne, mild acne, moderate acne, and severe acne. In 1931 Bloch reported that $57 \%$ of boys and $19 \%$ of girls had moderate to severe acne. ${ }^{6}$ These figures had fallen to $30 \%$ and $20 \%$ in $1971^{1}$ and to $35 \%$ and $13 \%$ in $1981 .^{7}$ Proportionally there was an even greater shift from the mild to minimal or subclinical groups in this study: we were unable to find any girls with worse than mild acne and only $1.8 \%$ of the boys had moderate acne.

During the same period the proportion of 12-17 year olds referred for specialist dermatology opinions declined. In 1967, 275 new patients with acne were referred to this department, of whom 98 (36\%) were aged 12-17. In 1977 this proportion had fallen to 62 (31\%) of 203 referrals and in 1987 to $45(21 \%)$ of 217 referrals. The reason for the decrease in severity of acne is not obvious. It has probably been due to an increase in awareness of appearance, increasing availability and use of over the counter preparations, and better management of acne by general practitioners. The low number of teenagers seeking advice from chemists is almost certainly an underestimate of the value of the pharmacist as a source of advice as many parents consult chemists on behalf of their children.

The economic cost of acne is potentially enormous. In 1974 in the United States it was estimated at $\$ 314$ million dollars ( $£ 200$ million): $\$ 190$ million for doctors' fees, $\$ 24$ million for prescribed treatments, and $\$ 100$ million for over the counter preparations. ${ }^{910}$ Similar figures are not available for the United Kingdom, but if dermatologists saw similar numbers of patients - that is, 21 per 1000 population each year - the cost to the hospital budget would be about $£ 58$ million if the consultation for each new outpatient is estimated to cost $£ 50$. Our results suggest that most cases of acne are managed well within the community and by general practitioners at a much lower cost.

We conclude that adolescent acne seems to be much less troublesome than it was 20 and 10 years ago. This is probably because of more extensive use of over the counter preparations as well as more suitable treatment by better informed general practitioners. The role of the dermatologist in the management of acne in this age group is minimal other than in educating primary health care workers.

We thank the department of community medicine of Greater Glasgow Health Board; the Strathclyde department of education; and the headmasters, members of staff, and pupils of the schools visited. We are also grateful to Dr W J Cunliffe and to Procter and Gamble Health and Beauty Care Europe for a grant.

1 Burton JL, Cunliffe WJ, Stafford I, Shuster S. The prevalence of acne in adolescence. Brf Dermatol 1971;85:119-26.

2 Cunliffe WJ, Gould DJ. Prevalence of facial acne vulgaris in late adolescence and in adults. $\mathrm{Br}$ Med $\mathcal{F}$ 1979;i:1109-10.

3 Munro-Ashman D. Acne vulgaris in a public school. Transactions of the $S_{t}$ fohn's Hospital Dermatological Society 1963;9:144-8.

Finlay SE. Physical diseases in university students. Br Med f 1976;ii:1312-4.

5 Burke BM, Cunliffe WJ. The assessment of acne vulgaris: the Leed technique. Br 7 Dermatol 1984;111:83-92.

6 Bloch B. Metabolism, endocrine glands and skin diseases, with special reference to acne vulgaris and xanthoma. Br f Dermatol 1931;43:61-87.

7 Fellowes $H M$, Billewicz WZ, Thomson AM. Is acne a sign of normal puberty? A longitudinal study. $\mathcal{F}$ Biosoc Sci 1981;13:401-7.

Kligman AM. An overview of acne. I Invest Dermatol 1974;62:268-87

9 Stern RS, Johnson ML, DeLozier J. Utilization of physician services for dermatologic complaints. The United States, 1974. Arch Dermatol 1977;113 $1062-6$

10 Kraning KK, Odland GF, for the Acne Study Group. Analysis of research need and priorities in dermatology. III. Acne. $\mathcal{f}$ Invest Dermato 1979;73:434-42.

(Accepted 21 February 1989)

\section{Availability of computed tomography of the brain in the United Kingdom}

\section{Richard Langton Hewer, Victorine A Wood}

Department of Neurology, Frenchay Hospital, Bristol BS16 1LE

Richard Langton Hewer, FRCP, consultant neurologist Victorine A Wood, MPHIL, research assistant

Correspondence to: Dr Langton Hewer.

BrMed J 1989;298:1219-20
Computed tomography of the brain has been used in the United Kingdom since 1974. The technique is now generally accepted as invaluable for investigating and managing intracranial disease. It also has cost benefits, with a major reduction in expensive and invasive investigations. ${ }^{1}$ In 1985 Thomson found that 108 computed tomographic scanners were in operation in the United Kingdom. We carried out a study to assess the position in 1987.

\section{Methods and results}

This study was undertaken with the collaboration of the services subcommittee of the Association of British
Neurologists. Details of the methods are reported elsewhere. ${ }^{2}$ A computed tomographic scanner was defined as a machine that was capable of, and available for, scanning the brain without financial charge to the patient. Mobile, whole body, and privately operated scanners were included provided that the above criteria were satisfied.

We identified 135 head scanners in the United Kingdom in June 1987. This number included two mobile scanners and one scanner in a private hospital. The table details distribution through the United Kingdom. Overall there was one head scanner to every 421000 people. There was considerable disparity between the best provided region (East Anglia), which had a ratio of one head scanner for 284000 people, and the least well provided region (Oxford), which had a ratio of one head scanner for 827000 people. The distribution of scanning facilities within regions was also uneven. For instance, nine of the 11 health districts in the South Western region $(82 \%)$ had their own head scanner, whereas only three of the 16 health districts in the Northern region $(19 \%)$ had a scanner. Overall, 27.67 million people - nearly $49 \%$ of the total 